\title{
Pisacano Memorial Foundation: Continuing the Tradition
}

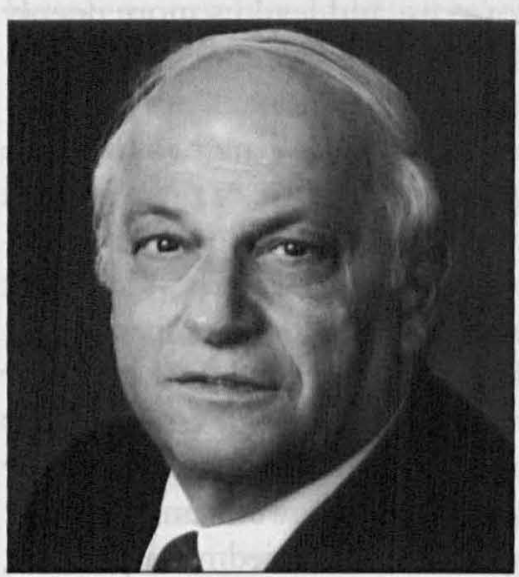

The Nicholas J. Pisacano, MD, Memorial Foundation, Inc. was created in 1990 by the American Board of Family Practice (ABFP) in tribute to the founder and first executive director of the ABFP, Nicholas J. Pisacano, MD (1924-1990)

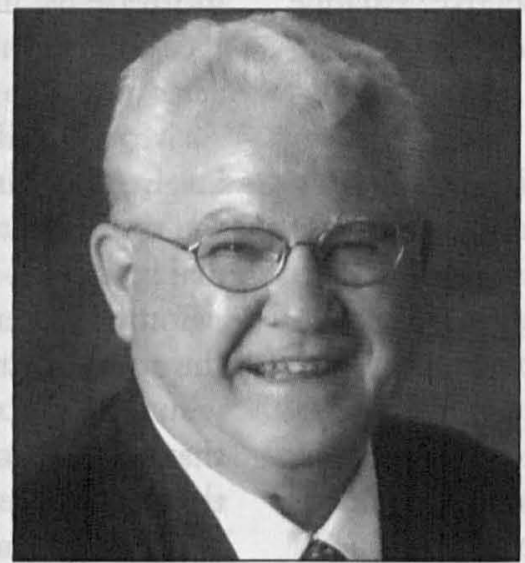

Paul R. Young, MD-ABFP Executive Director (1990-1997) and founding member of the Pisacano Memorial Foundation. Today he serves as Senior Executive of the ABFP and as a member of the Board of Directors of the Foundation.

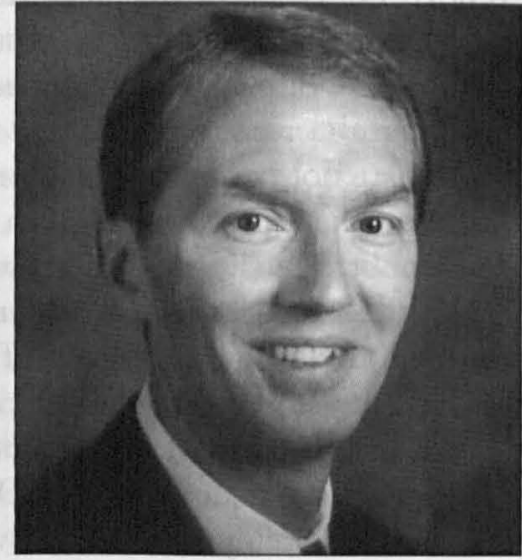

Robert J. Cattoi, Executive Director since 1992, came to the foundation from the Texas Tech School of Medicine where he served as Assistant Dean for Strategic Planning and Program Development.
The Pisacano Memorial Foundation in Lexington, Kentucky, was chartered in January 1991 by the American Board of Family Practice (ABFP) as an enduring tribute to its founder and first executive director, Nicholas J. Pisacano, MD. Dr. Pisacano is widely accredited as one of the leaders of family practice who sought to have it recognized as a major specialty.

After Dr. Pisacano's death in 1990, Paul Young, MD, ABFP Executive Director (1990-1997), assembled the ABFP's executive committee and "friends of Nick" to create a commemorative activity that would continue Dr. Pisacano's work and vision. The result of this effort was the formation of the Nicholas J. Pisacano, MD, Memorial Foundation. The Foundation was chartered as a 501.c. 3 nonprofit organization with its defined primary mission to develop a permanent fund that provides scholarships and leadership training to outstanding medical school students who are committed to a career in family practice.

The Pisacano Memorial Foundation is overseen by a board of directors made up of family practice diplomates and corporate members with affiliations to medicine. Dr. Robert Avant, Executive Director of the ABFP, serves as President of the Foundation and Dr. Paul Young, Senior Executive of the ABFP, is a member of the Foundation's Board of Directors.

The professional staff is led by Robert J. Cattoi, its first Executive Director. Mr. Cattoi came to the Foundation in 1992 from the Texas Tech School of Medicine where he served as Assistant Dean for Strategic Planning and Program Development.

The Pisacano Memorial Foundation has awarded scholarships to 40 medical students since 1993 . Today, 17 Pisacano Scholars are practicing physicians and 23 are currently attending medical school or are in residency programs across the country.

Following is a conversation with Robert Cattoi.

There are hundreds of medical foundations, scholarships, grants and loan programs for students. What makes the Pisacano Memorial Foundation and the Pisacano Scholars Program different?

CATTOI: Dr. Pisacano realized many years ago there was an unspoken competition among medical specialties to attract the best and the brightest medical students. He loved family medicine, and he dedicated his life's work to it. He was a strong proponent of family medicine's role as the front line of health care delivery. Dr. Pisacano knew then, as we know today, that for the patients to get the best care available, family medicine had to be stronger. He also believed that to make the specialty stronger, they needed to attract the highest quality young men and women who show a passion for delivery of health care. The Pisacano Scholars are well known as these types of men and women. They are some of the finest medical students in the country.

Our Foundation's staff take very seriously our role in continuing the hard work and dedication that Dr. Pisacano and his colleagues put into making family practice the specialty it is today.

We feel that the identification of the Pisacano Scholars insures the success of the discipline.

\section{Who is eligible for the Pisacano Scholars Award?}

CATTOI: All second- and third-year medical students who are committed to family practice are encouraged to apply. There is no cost to submit an application. 
How are the Pisacano Scholars selected?

CATTOI: We mail applications to all medical school chairs and financial aid officers every October with a submission deadline of March 1. The applicant must submit letters of recommendation from a family physician, their family practice or primary care department, and their dean's office from their respective schools. They must also supply a complete academic background, placement, and volunteer activity description. Each candidate is then interviewed by a board-certified family physician. Each interview is documented and sent to the Foundation to become part of their application. Two members of the screening committee will then review the application. At this point, the selection team narrows the list of applicants to the top 20. The Foundation Board meets for a 2-day period to review each of the finalists' applications. Selections are made and the candidates are contacted. The Pisacano Scholars are reviewed each year throughout their medical school and residency efforts. Should they leave the specialty of family practice, their scholarship will be revoked.

\section{What do you look for in candidates?}

CATTOI: Each of the 40 Scholars that we have selected since 1993 has shown a strong work ethic, excellent communication skills, outstanding academic achievements and have an extensive history of volunteerism and leadership. Examples of their volunteering and leadership efforts are starting and working in underserved clinics in urban, rural, and international settings. They lead family medicine efforts in both their medical school and state organizations, and represent family practice on national committees.

\section{What do the students receive when they are selected as a Pisacano Scholar?}

CATTOI: Each Pisacano Scholar receives a scholarship valued at up to $\$ 10,000$ per year for up to 5 years or until they have finished their residency. The scholarship is intended to defray a portion of their medical school expenses. The scholarship is not a loan, and it has no stipulations except that each Scholar must maintain a strong commitment to family practice.

A portion of this scholarship is earmarked for each Scholar to attend leadership training and skills-build- ing conferences throughout the year. The Foundation encourages each Scholar to attend these specially designed conferences, where they are introduced to the art of negotiation, written and oral communication, group leadership and issue leadership.

\section{What does the Foundation expect from the Pisacano Scholars upon their graduation?}

CATTOI: We expect the Scholars to become leaders in their home communities, the medical community and in family practice by being a positive influence on the health of people through the enhancement of our specialty. Dr. Pisacano always believed that physicians should give something back in their practice and the way they live their lives. We firmly believe that our Scholars should and will give back to the communities they serve and to the specialty of family practice.

\section{How does the Foundation generate funds?}

CATTOI: The Foundation receives contributions from individuals and corporations from around the country. We have established a number of programs and giving levels for each. As a 501.c.3 nonprofit corporation, we are able to provide programs that include planned giving and direct gifts which benefit both the Foundation and the contributor. It is important to note that all contributions are tax deductible and are strictly used for scholarships. None of the contributed monies are used for administrative fees.

\section{As you look to the future, how do you see the Foundation and its Scholars affecting primary care?}

CATTOI: To summarize, Dr. Pisacano believed in a sequence of priorities for everything we do: "what is the best for the people, what is the best for medicine, and what is the best for family practice." The Foundation and its Scholars embody this belief. In the future, you will find our scholars active in a number of different settings, such as, practicing in communities throughout the United States, precepting medical students, or occupying leadership positions in medical organizations or governmental roles.

No matter where they end up, they will be the future leaders of family practice and as such, they will play an important role in providing cost-effective care to all people.

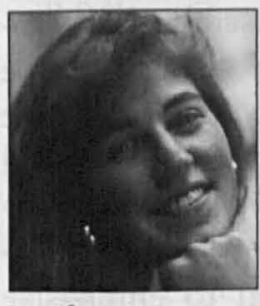

Jennifer DeVoe

Helena, MT

Montana State Univ.

Havvard Medical School

\section{Pisacano Scholars}

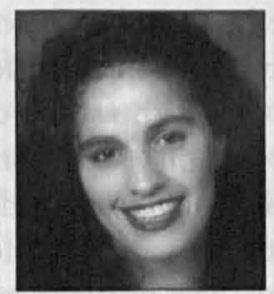

Marguerite Duane Higbland Hills, $N Y$ Cornell University SUNY - Stony Brook

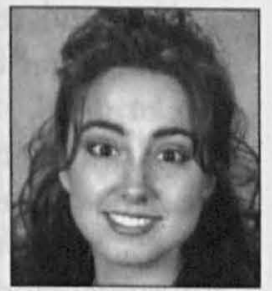

English Hairrell Brimingham, $A L$. Birmingbam Southern College Univ. of Alabama-Birm.

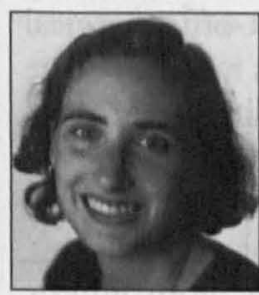

Nerissa Koehn Missoula, $M T$ Lewis bे Clark College Harvard Medical School

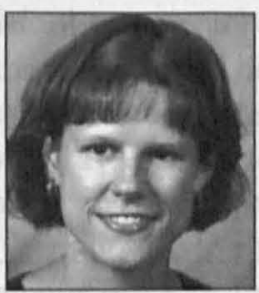

Jennifer Lochner Waupaca, WI Univ. of WI-Madison Univo of Wisconson Medical School

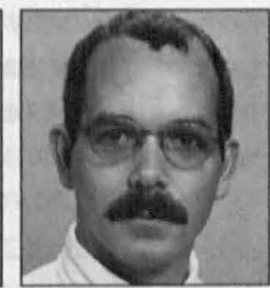

James Toombs Salem, $M O$

Southeast Missouri State University Univ. of Missouri 